\title{
The Optimal Carbon Reduction and Return Strategies under Carbon Tax Policy
}

\author{
Jia Wang ${ }^{1}$ and Xijia Huang ${ }^{2, *}$ \\ 1 School of Tourism, Tourism Research Institute, Nanchang University, 999 Xuefu Avenue, \\ Nanchang 330031, China; wangjia2014@ncu.edu.cn \\ 2 Jiangxi Development Research Institute, School of Tourism, Nanchang University, 999 Xuefu Avenue, \\ Nanchang 330031, China \\ * Correspondence: Jua.Wange@nau.edu; Tel.: +86-0791-83969108
}

Received: 21 June 2018; Accepted: 13 July 2018; Published: 14 July 2018

check for updates

\begin{abstract}
Recently, consumers have been increasingly shopping due to the development of e-commerce; thus, many traditional firms producing green products are entering e-commerce platforms to sell products for their survival. In the contexts of online sales and carbon tax policy, firms need to determine an optimal carbon reduction level and online return strategies. To address firms' decision-making challenges, we consider a firm producing and selling its green products via an e-commerce platform. For optimal online return strategies, we find that if the residual value of the returned product is relatively small, the firm should not offer an online return service; otherwise, the firm should offer this service. Moreover, the results show that carbon tax policy is detrimental to the firm and consumers, while increasing the average customer satisfaction rate of the product benefits the firm and consumers. Interestingly, we find that the platform should reduce its referral fee as the unit carbon tax increases.
\end{abstract}

Keywords: carbon tax policy; return policy; carbon reduction; e-commerce platform

\section{Introduction}

In recent years, environmental pollution has attracted increasing attention from governments, firms and consumers. For instance, to curb carbon emissions, many countries such as Finland, Norway, Sweden, Denmark, the Netherlands, Germany, United Kingdom and Australia have enacted carbon tax policy [1]. In the context of a carbon tax policy, firms need to adopt green production technology to improve product carbon reduction levels [2-4]. Moreover, with the development of e-commerce, consumers are increasingly shopping online rather than shopping offline. A report shows that online sales in the USA in 2017 reached $\$ 453.46$ billion, which is an increase of $16 \%$ compared with that in 2016 [5]. In addition, some e-commerce giants such as Amazon.com and Tmall.com dominate the e-commerce market, and some firms, as third-party sellers, therefore sell their products on e-commerce platforms [6,7]. Compared with the case in the absence of online sales, a carbon tax policy taking online sales into account may have different effects on the competition between e-commerce platforms and third-party sellers and the optimal decisions of these members. Compared with the case in the absence of carbon tax policy, the competition between platforms and third-party sellers in the presence of a carbon tax policy may be stiff, and the optimal decisions of these members in the presence of a carbon tax policy may be changed. Thus, considering the case of a carbon tax policy and the fact that consumers are increasingly shopping online, firms producing green products and selling products via e-commerce platforms need to determine an optimal product price and product carbon reduction levels, and e-commerce platforms need to decide an optimal referral fee for firms per unit product 
sold. How does carbon tax policy affect the optimal product price, carbon reduction level and referral fee? These questions are worth studying.

Firms who sell their products online need to consider the online return problem. Many scholars have presented the fact that the online product return rate is much larger than the offline product return rate [8]. In this context, firms face the challenge of whether or not to offer online return services. Moreover, the psychological cost of consumers' waiting times for online shopping and shipping costs should be taken into account when addressing the problems of online strategies. It is important to note that our paper focuses on firms who produce and sell green products. If firms do not offer online return services, the firms offer free shipping services to consumers for online shopping, and consumers who buy products need to wait for the arrival of products. After buying products, some consumers find that the products are unfit for their use, but they cannot return these products, which certainly will reduce consumer utility. In the context of firms without online return services, the firms do not need to bear losses from returned products, but product demand may decline due to decreased consumer utility. In addition, if firms offer online return services, consumers can return their products but need to undertake the shipping cost of returned products. Considering that the product price is larger than the shipping cost, increased consumer utility improves product demand. However, the firms need to undertake losses from returned products. Thus, should firms offer online return services? How does carbon tax policy affect the optimal online return strategy? There is no previous research studying these questions; we are therefore addressing them here.

In our paper, we consider a firm producing and selling green products via an e-commerce platform. The government enacts a carbon tax policy in which the government taxes the firm for their per unit carbon emission. The firm is a third-party seller of the platform, and there is a Stackelberg game between the platform and the firm. According to the firm with and without an online return service, we develop two theoretical models: i.e., model NR (the firm without online return service) and model YR (the firm with online return service). The paper investigates the optimal product retail price, carbon reduction level, referral fee, the firm's profit and consumer surplus under the models NR and YR, respectively, and explores the optimal online return strategy for the firm. Some managerial insights are obtained, which serve firms to determine their optimal carbon reduction and return strategies and platforms to set an optimal referral fee.

The rest of our paper is arranged as follows. Section 2 presents related literature and the contributions of this paper. In Section 3, the problems of determining the optimal carbon reduction and return strategies under carbon tax policy have been described, and consumer utility functions, product demand functions and cost structures have been proposed. Two theoretical models (i.e., models NR and YR) are developed in Section 4, and we also present optimal solutions for the firm and the platform. Section 5 analyzes the optimal return strategy and presents some other results. In tSection 6 , managerial insights are concluded. Finally, the Appendix presents the proofs.

\section{Literature Review}

The paper investigates optimal carbon reduction and online return strategies of a firm selling on an e-commerce platform under a carbon tax policy. Thus, the related literature can be divided into two streams, i.e., the research on carbon tax policy and the research on return strategies.

The first stream investigates operational and optimization problems considering carbon tax policy. Some scholars have examined optimal carbon tax policy. In the last century, Poterba [9] investigated the design and implementation of a carbon tax policy which can be used to curb carbon emissions. Then, Roughgarden and Schneider [10] have taken the uncertainties of climatic effects into account to get an optimal carbon tax via developing a dynamic integrated climate-economy model and show that the optimal carbon tax policy considering most of these alternate damage estimates is more aggressive than that considering a single damage function. Metcalf [11] designed a carbon tax policy to reduce U.S. greenhouse gas emissions and provides a distributional analysis of a neutral approach. Zhou et al. [12] explored an optimal carbon tax policy via maximizing the social welfare function and 
also take consumer environmental awareness into account. Besides optimal carbon tax policy, many scholars have studied the impacts of carbon tax policy on the optimal solutions of firms. Nordhaus [13] developed a "DICE" model to investigate the optimal greenhouse-gas reductions under carbon tax policy. Goulder and Mathai [14] further studied carbon abatement considering induced technological change and found that the effect on the timing of abatement is analytically ambiguous when knowledge is generated via learning-by-doing. Chen and Hao [15] studied the impacts of carbon tax policy on the sustainable pricing and production policies of two competing firms and showed that a firm obtains a larger carbon emissions reduction percentage if they undertake a higher carbon tax. Yu and Han [16] investigated the impacts of carbon tax policy on product retail price and total carbon emission in a supply chain with a manufacturer and a retailer and designed two contracts to coordinate the supply chain. Wang et al. [17] studied the optimal production decisions of new and remanufactured products under carbon tax policy and found that manufacturers can offset the cannibalization and curb carbon emissions via adopting low-carbon emission technology.

The first stream mainly focuses on optimal carbon tax policy for governments and optimal decisions under carbon tax policy for firms. Although our paper takes carbon tax policy into account, our paper analyzes the impacts of carbon tax policy on firm's optimal product price and carbon reduction level strategies and platforms' optimal referral fees, which have not been studied before.

The second stream investigates return strategies. Return strategies analysis has sustained the interest of many scholars [18-20]. For instance, Lau and Lau [21] studied the optimal product price and return strategies of a manufacturer and showed that a shrewd manufacturer can use a return-credits agreement to earn more profits. Mukhopadhyay and Setoputro [22] designed a profit maximization model to investigate optimal return policy, and the results can serve firms to determine optimal decisions. In contrast to the traditional offline return policies, online return policies with the advent of e-commerce are increasingly receiving attention from firms and scholars. Mukhopadhyay and Setoputro [23] developed a theoretical model to investigate optimal product price and online return strategies. Li et al. [24] examined the relationships between return policy, product quality and pricing strategy in the context of online sales. Bower and Maxham [25] used two surveys and actual customer spending dates to indicate normative assumptions and the long-term consequences of fee and free returns and presented the idea that online retailers should offer either a free online return policy or a minimum fee return policy if they can determine consumers' reactions to fee returns. Altug and Aydinliyim [26] studied how consumers' discount-seeking purchase deferrals affect the return policy of online retailers and found that retailers in some conditions can gain a competitive advantage when selling to strategic consumers. Sahoo et al. [27] explored the impact of online product reviews on the optimal online return strategy and showed that unbiased online reviews benefit consumers and that biasing reviews upwards results in more returns.

The second stream studies offline return and online return policies from multiple backgrounds and perspectives. However, the online return policies of e-commerce platforms' third-party sellers have not been studied, which is our contribution to the research. Moreover, the impacts of carbon tax policy and online return policy on carbon reduction level have also not been studied before, and these have been considered in our paper.

\section{Problem Description}

We consider a firm who produces green products. The government enacts carbon tax policy, which means that the government charges the firm for their per unit carbon emission. Under this policy, the firm will improve its carbon emission reduction level to curb total emissions. Considering the online shopping habits of consumers, the firm sells its products via an e-commerce platform. The firm is a third-party seller of the platform and determines its product retail price and pays the referral fee to the platform per unit product sold. Moreover, the firm needs to choose whether or not to offer a return service, considering the relatively high online return rate. Based on a firm with and without online 
return services, our paper develops two corresponding models. To clarify our model, some notations are introduced in Table 1.

Table 1. Notations.

\begin{tabular}{ll}
\hline Notation & \multicolumn{1}{c}{ Description } \\
\hline$p$ & Product retail price \\
$e$ & Carbon emission reduction level \\
$f$ & Referral fee \\
$e_{I}$ & Initial unit carbon emission \\
$\alpha$ & Average customer satisfaction rate of the product \\
$b$ & Consumer's sensitivity to carbon emission reduction level \\
$c$ & Unit production cost \\
$h_{S}$ & Unit shipping cost \\
$h_{w}$ & Psychological cost of consumer waiting times for online \\
$v$ & shopping \\
$t$ & Unit residual value of returned product \\
$\prod_{i}$ & Unit carbon tax \\
\hline
\end{tabular}

According to the firm's return strategies, there are two scenarios: one is a firm without an online return service (NR) and the other is a firm with an online return service (YR). Moreover, we use the superscripts NR and YR to represent the two scenarios in our paper. Note that if the average customer satisfaction rate is equal to 1 , there are no consumer returns, which means that $Y R$ is identical with NR.

Cao et al. [28] investigated the optimal trade-in strategies of a retailer with online and offline sales channels and assumed that consumers are heterogeneous with respect to their valuation for a new product. Similar to them, we assume that consumers are heterogeneous with respect to their willingness-to-pay for the green product $\phi$ which is a random variable with cumulative distribution function $F(\phi)$. To simplify our model, we assume that $\phi$ is uniformly distributed on $[0,1]$, and the market size is normalized to 1 . Moreover, the psychological cost of consumer waiting for online shopping $h_{w}$ is considered in our model.

Under the case of $N R$, the firm does not offer an online return service. The average customer satisfaction rate of the product is $\alpha$, which means that consumers with $1-\alpha$ percent will not be satisfied by the products which are purchased by them. We assume that if products are unfit for consumers, consumers under NR cannot obtain utility from these products. Thus, the utility function of consumers from online shopping is given as follows:

$$
u^{N R}=\alpha\left(\phi-p+b e-h_{w}\right)+(1-\alpha)\left(-p-h_{w}\right)
$$

If $u^{N R} \geq 0$, consumers will purchase green products from the firm. If setting $u^{N R}=0$, we have $\phi^{N R}=\left(p+h_{w}\right) / \alpha-b e$, which means that, for a consumer at point $\phi^{N R}$, there is no difference between purchasing a green product and not purchasing it. Thus, the product demand function under NR is

$$
D^{N R}=\int_{\phi^{N R}}^{1} d F(\phi)=\left[1+b e-\left(p+h_{w}\right) / \alpha\right]
$$

Under the case of $Y R$, the firm offers an online return service. If the products are unfit for consumers, consumers can return these products to obtain their paid prices but need to undertake the shipping costs of returned products. Thus, the utility function of consumers under YR from purchasing green products is

$$
u^{Y R}=\alpha\left(\phi-p+b e-h_{w}\right)+(1-\alpha)\left(-h_{w}-h_{s}\right)
$$

if $u^{Y R} \geq 0$, consumers will purchase green products from the firm. If we set $u^{Y R}=0$, we have $\phi^{Y R}=p-b e+\left(h_{w}+h_{s}-\alpha h_{s}\right) / \alpha$, which means that, for a consumer at point $\phi^{Y R}$, there is no 
difference between purchasing a green product and not purchasing it. Thus, the product demand function under YR is

$$
D^{Y R}=\int_{\phi^{Y R}}^{1} d F(\phi)=1-p+b e-\left(h_{w}+h_{s}-\alpha h_{s}\right) / \alpha
$$

Moreover, we assume that the total carbon emission is equal to $\left(e_{I}-e\right) q$, which can be supported by Cao et al. [29]. Thus, the firms should pay $t\left(e_{I}-e\right) q$ to the government for its total carbon emission. Similar to Ji et al. [2], we assume that the carbon reduction cost is $e^{2} / 2$. Besides this, we assume that the firm offers a free shipping service to consumers who purchase products.

E-commerce giants such as Amazon.com, JD.com, Tmall.com are dominating e-commerce markets; thus, there is a Stackelberg game between the firm and the platform, where the firm is the follower and the platform is the leader. We assume that the platform will not charge the firm the referral fee if the sold products are returned, which is in accordance with return policies of Amazom.com, JD.com etc.

\section{Theoretical Models}

In this section, there are two models: model NR (a firm without a return service) and model YR (a firm with a return service). The platform who is the leader needs to determine the referral fee $f$. The firm who is the follower needs to determine its product retail price $p$ and carbon reduction level $e$.

\subsection{Model NR}

Under model NR, the firm does not offer an online return service. Thus, the problem of the firm under NR is described as follows:

$$
\max \prod_{F}^{N R}(p, e)=D^{N R}\left[p-f-c-h_{s}-t(\bar{e}-e)\right]-e^{2} / 2
$$

and the problem of the platform under NR is

$$
\max \prod_{P}^{N R}(f)=D^{N R} f
$$

The consumer surplus under NR is given as follows:

$$
C S^{N R}=\int_{\phi^{N R}}^{1}\left[\alpha\left(\phi-p+b e-h_{w}\right)+(1-\alpha)\left(-p-h_{w}\right)\right] d F(\phi)
$$

By solving Equations (5) and (6) via backward induction, the optimal solutions under NR are easily obtained, which are presented in Table 2.

Table 2. The optimal solutions.

\begin{tabular}{cl}
\hline \multicolumn{1}{c}{ Models } & \multicolumn{1}{c}{ The Optimal Solutions } \\
\hline \multirow{4}{*}{ NR } & $p^{N R^{*}}=\alpha\left[1-\left(1-b t-\alpha b^{2}\right)\left(\alpha-c-h_{s}-h_{w}-e_{I} t\right) /(2 A)\right]-h_{w} ;$ \\
& $e^{N R^{*}}=(t+\alpha b)\left(\alpha-c-h_{s}-h_{w}-e_{I} t\right) /(2 A) ;$ \\
& $f^{N R^{*}}=\left(\alpha-c-h_{s}-h_{w}-e_{I} t\right) / 2 ;$ \\
& where $A=2 \alpha-\alpha^{2} b^{2}-2 \alpha b t-t^{2}$. \\
& $p^{Y R^{*}}=1-\left(1-b t-\alpha b^{2}\right)\left(\alpha+v+\alpha h_{s}-c-2 h_{s}-h_{w}-\alpha v-\right.$ \\
YR & $\left.e_{I} t\right) /(2 A)-\left(h_{w}+h_{s}-\alpha h_{s}\right) / \alpha ;$ \\
& $e^{Y R^{*}}=(t+\alpha b)\left(\alpha+v+\alpha h_{s}-c-2 h_{s}-h_{w}-\alpha v-e_{I} t\right) /(2 A) ;$ \\
& $f^{Y R^{*}}=\left(\alpha+v+\alpha h_{s}-c-2 h_{s}-h_{w}-\alpha v-e_{I} t\right) /(2 \alpha)$. \\
\hline
\end{tabular}

\subsection{Model $Y R$}

Under YR, the firm offers an online return service. Thus, the problem of the firm under YR is

$$
\max \prod_{F}^{Y R}(p, e)=D^{Y R}\left[\alpha(p-f)+(1-\alpha) v-c-h_{s}-t(\bar{e}-e)\right]-e^{2} / 2
$$


and the problem of the platform is

$$
\max \prod_{P}^{Y R}(f)=\alpha D f
$$

The consumer surplus under $Y R$ is given as follows:

$$
C S^{Y R}=\int_{\phi^{Y R}}^{1}\left[\alpha\left(\phi-p+b e-h_{w}\right)+(1-\alpha)\left(-h_{w}-h_{S}\right)\right] d F(\phi)
$$

By solving Equations (8) and (9) via backward induction, the optimal solutions under NR are easily obtained, which are also presented in Table 2 above.

\section{The Results and Analyses}

In this section, we present the optimal return strategy of the firm and analyze the optimal product retail price, carbon reduction level, referral fee, the optimal profits of the firm and the platform and optimal consumer surplus.

In the contexts of carbon tax policy and online sales, how does the firm determine its online return strategy? The following Theorem answers this question.

Theorem 1. The optimal return strategy depends on the magnitudes of the unit shipping cost and residual value of returned product, i.e.,

(a) if $0 \leq v<h_{s}$, we have $\prod_{F}^{N R^{*}}>\prod_{F}^{Y R^{*}}$;

(b) and if $v \geq h_{s}$, we have $\prod_{F}^{N R^{*}} \leq \prod_{F}^{Y R^{*}}$.

Theorem 1 shows that, if the residual value of the returned product is less (larger) than a threshold, the firm under NR has a larger (lower) profit than that under YR. A relatively small residual value of returned product means that the firm would undertake a huge loss from returned products. Although offering an online return service can entice more consumers to purchase products, the firm will not choose to offer an online return service considering the possible huge losses from returned products. However, if the residual value of returned product is relatively large, the firm only needs to bear a small loss from returned products. A firm which offers an online return service can thereby entice more consumers to purchase green products. Thus, in this context, the firm will choose to offer return service to pursue maximal profits.

Additionally, the conditions $0 \leq v<h_{s}$ and $v \geq h_{s}$ also mean that the unit shipping cost is larger and less than a threshold value. If the unit shipping cost is larger than the threshold, consumers who want to return their products need to undertake a huge cost, which reduces consumer utility from purchasing products. Thus, in the context of a relatively large unit shipping cost, if the firm offers an online return service, product demand increases slightly, but the firm will bear losses from returned products. Thus, the firm will not choose to offer an online service and vice versa.

Theorem 1 implies that, if the residual value of the returned product is relatively small, the firm should not offer an online return service; otherwise, the firm should offer an online return service. In other words, if the unit shipping cost is relatively large, the firm should not offer an online return service; otherwise, the firm should offer it.

Besides the impact of the return service on the firm's profit, the impact of the return service on consumer surplus is also necessary to investigate, and is given in the following Theorem.

Theorem 2. The impact of the online return service on consumer surplus is presented as follows:

(a) if $0 \leq v<h_{S}$, we have $C S^{N R^{*}}>C S^{Y R^{*}}$;

(b) and if $v \geq h_{s}$, we have $C S^{N R^{*}} \leq C S^{Y R^{*}}$.

Theorem 2 shows that, if the residual value of the returned product is less (larger) than a threshold, consumer surplus under model NR is larger (less) than that under model YR. In the context of a 
relatively small residual value, a firm with an online return service has no motivation to entice consumers to buy green products, thus consumers under model YR obtain less utility than that under model NR. Otherwise, if the residual value of the returned product is relatively large, a firm with an online return service has motivation to entice more consumers, and thus consumers under model YR obtains more utility than that under model NR.

Theorem 2 implies that, if the residual value of the returned product is relatively small (large), the online return service harms (benefits) consumers. Moreover, combining Theorem 1 and Theorem 2, we find that a firm's optimal return strategy harms consumers.

The firm's online return strategy may affect the optimal product price, the optimal carbon reduction level and the optimal referral fee. To investigate the impacts, we present the following propositions.

Proposition 1. The impacts of an online return strategy on the optimal product retail price is given as follows: if $0 \leq v<\bar{v}$, we have $p^{N R^{*}}<p^{Y R^{*}}$; otherwise, we have $p^{N R^{*}} \geq p^{Y R^{*}}$, where $\bar{v}=3 \alpha+c+e_{I} t-3 h_{w}+$ $\left[2\left(t^{2}-\alpha^{2} b^{2}\right)\left(\alpha-h_{s}-h_{w}\right)+2 \alpha h_{s}\left(1-\alpha b^{2}-b t\right)\right] /\left(\alpha^{2} b^{2}+t \alpha b-\alpha\right)$.

Proposition 1 shows that, if the residual value of the returned product is less (larger) than a threshold, the firm under model NR should set a lower (higher) product retail price than that under model YR. If the residual value of the returned product is relatively small, the firm will undertake a huge loss from returned products, and thus a firm with an online return service will set a higher product retail price than that without an online return service to make up for the loss from returned products. Otherwise, the firm only bears a little loss from returned products, and thus a firm with an online return service will set a lower product retail price than that without an online return service to entice more consumers.

Proposition 1 implies that, if the residual value of the returned product is relatively small (large), a firm with an online return service compared to that without a return service should set a higher (lower) product retail price.

Proposition 2. The impacts of an online return strategy on the optimal carbon reduction level is given as follows: if $0 \leq v<h_{s}$, we have $e^{N R^{*}}>e^{Y R^{*}}$; otherwise, we have $e^{N R^{*}} \leq e^{Y R^{*}}$.

Proposition 2 shows that, if the residual value of the returned product is less (larger) than the unit shipping cost, the optimal carbon reduction level under NR is larger (less) than that under YR. In the context of a relatively small residual value, a firm with an online return service compared with that without an online return service has no motivation to improve carbon reduction levels considering the huge loss from returned products. Otherwise, a relatively large residual value entices a firm with an online return service to improve its carbon reduction level to entice more consumers.

Proposition 2 implies that, if the residual value of the returned product is relatively small (large), a firm with a return service compared with that without a return service should reduce (improve) its carbon reduction level.

Proposition 3. The impacts of online return strategy on the optimal referral is given as follows: if $0 \leq v<$ $2 h_{s}+c+h_{w}+e_{I} t-\alpha$, we have $f^{N R^{*}}>f^{Y R^{*}} ;$ otherwise, we have $f^{N R^{*}} \leq f^{Y R^{*}}$.

Proposition 3 shows that, if the residual value of the returned product is less (larger) than a threshold, the optimal referral fee under model NR is larger (less) than that under model YR. In the context of a relatively small residual value of returned product, a firm with an online return service undertakes huge losses from these returned products, and thus the platform should reduce the referral fee to entice the firm to adjust its product retail price, which affects consumers choices. Otherwise, a firm offering a return service can obtain more profits from increased demands, and thus the platform should improve its referral fee to obtain more profit. 
Proposition 3 implies that, if the residual value is relatively small (large), the platform under model YR compared with that under model NR should reduce (increase) its referral fee.

From Table 2, it is easy to find that the unit carbon tax and average customer satisfaction rate of the product affect the optimal solutions, profits and consumer surplus. To investigate these impacts, we develop two numerical examples.

In the first numerical example, we set $\alpha=0.8, b=0.1, c=0.2, h_{s}=0.05, v=0.1, e_{I}=0.3$, $h_{w}=0.05$, and vary $t$ from 0 to 0.1 . The impacts of unit carbon tax on the optimal solutions, profits and consumer surplus are depicted in following figures.

From Figures 1-5, we find that the optimal product retail price and carbon reduction level increase with unit carbon tax. As unit carbon tax increases, the firm should improve carbon reduction levels to reduce carbon emission costs and also should increase their product retail price to earn profit. Moreover, it is demonstrated that with the optimal referral fee, the firm's profit and consumer surplus decrease with unit carbon tax. As unit carbon tax increases, the firm will increase their product retail price, which will reduce consumers' willingness-to-pay. Thus, the platform will reduce its referral fee to entice more consumers to buy products indirectly. Furthermore, it is intuitive that increased carbon tax has negative effects on the firm's profit and consumer surplus.

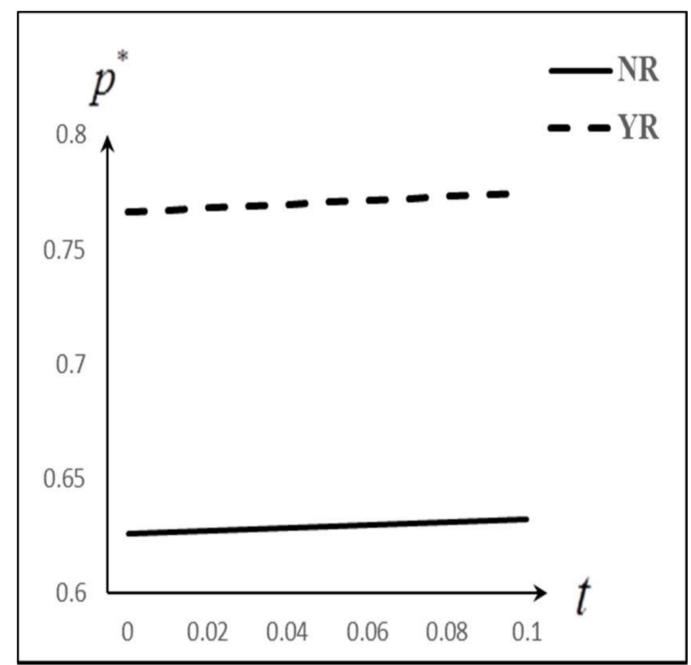

Figure 1. The optimal $p^{*}$ with respect to $t$.

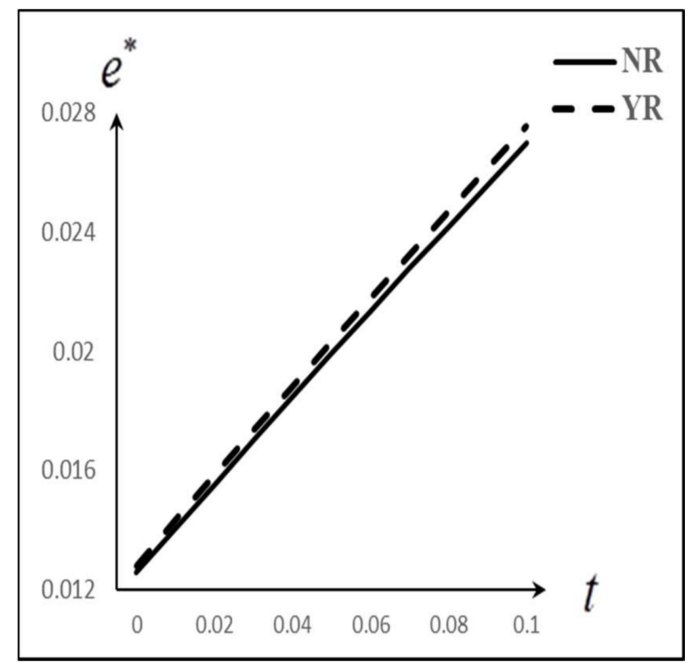

Figure 2. The optimal $e^{*}$ with respect to $t$. 


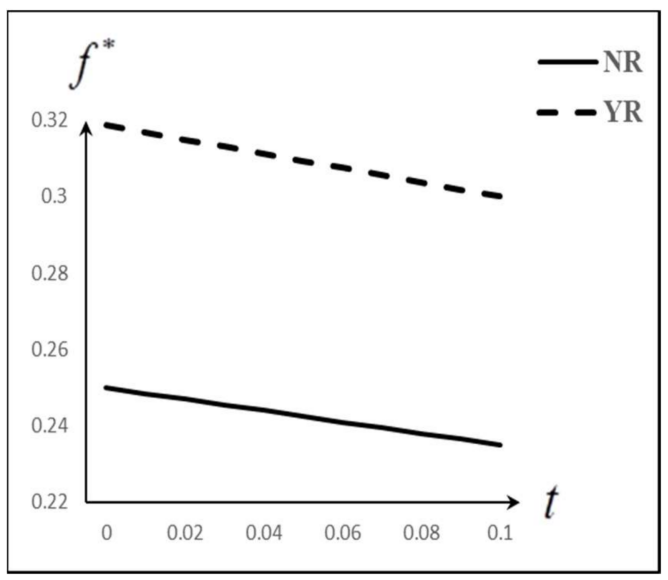

Figure 3. The optimal $f^{*}$ with respect to $t$.

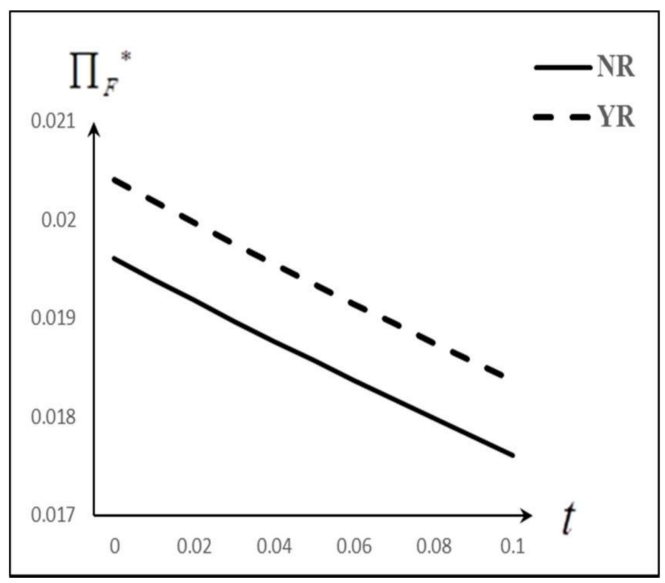

Figure 4. The optimal $\prod_{F}{ }^{*}$ with respect to $t$.

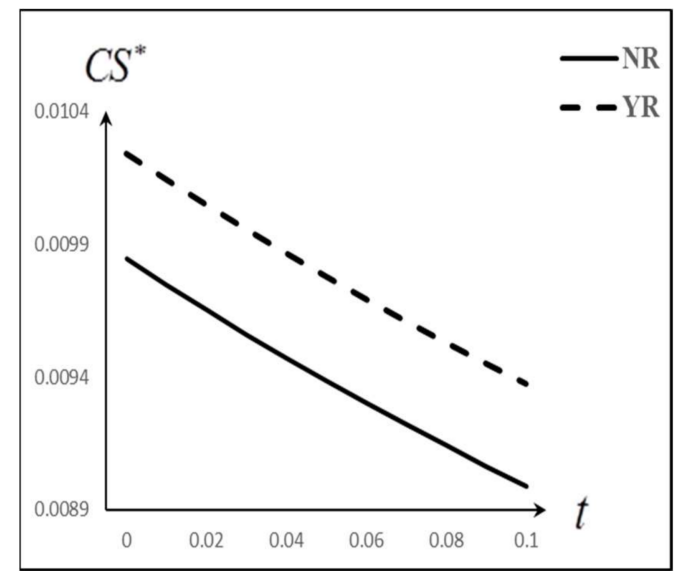

Figure 5. The optimal $C S^{*}$ with respect to $t$.

Figures 1-5 imply that carbon tax policy harms the firm and consumers, and that the platform should reduce its referral fee as the unit carbon tax increases.

In the second numerical example, we set $t=0.05, b=0.1, c=0.2, h_{s}=0.05, v=0.1, e_{I}=0.3$, $h_{w}=0.05$, and vary $\alpha$ from 0.6 to 1 . The impacts of the average customer satisfaction rate of the product on the optimal solutions, profits and consumer surplus are depicted in following figures. 
From Figures 6-10, we can observe that the optimal product retail price, carbon reduction level, referral fee, the firm's profit and consumer surplus increase with the average customer satisfaction rate of the product. As the average customer satisfaction rate of the product increases, a consumer's utility from purchasing a product increases, which increases product demand. In this context, a firm can increase their product retail price to earn more unit profit, and the platform can increase their referral fee to earn more transaction profit from the firm. Moreover, the firm has more motivation to improve carbon reduction levels to entice more consumers to buy products.

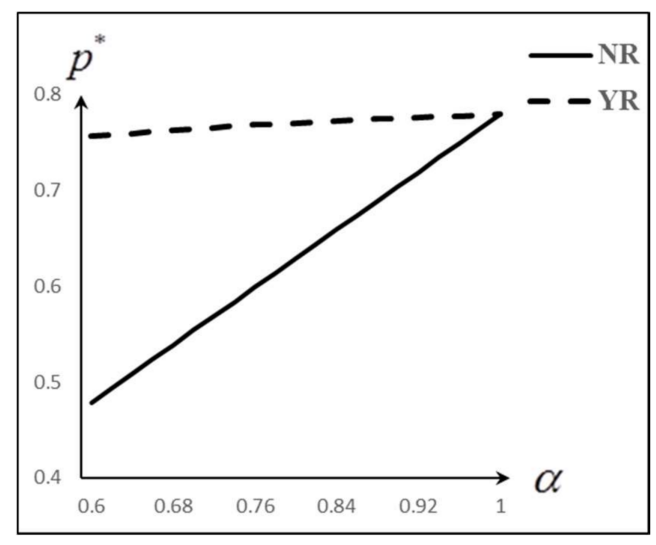

Figure 6. The optimal $p^{*}$ with respect to $\alpha$.

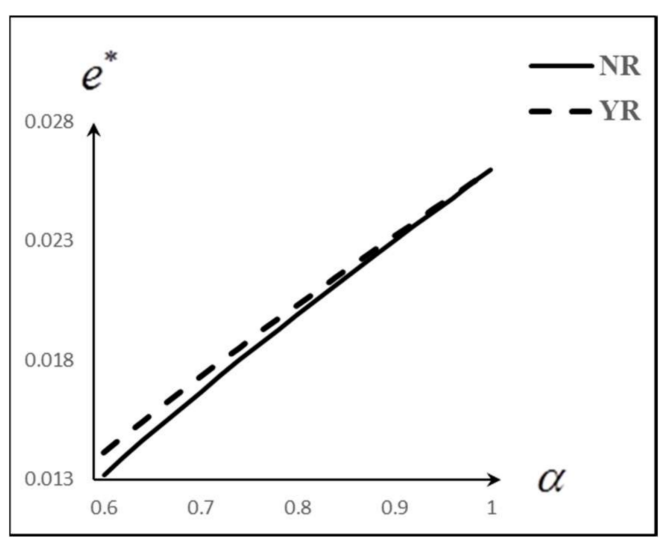

Figure 7. The optimal $e^{*}$ with respect to $\alpha$.

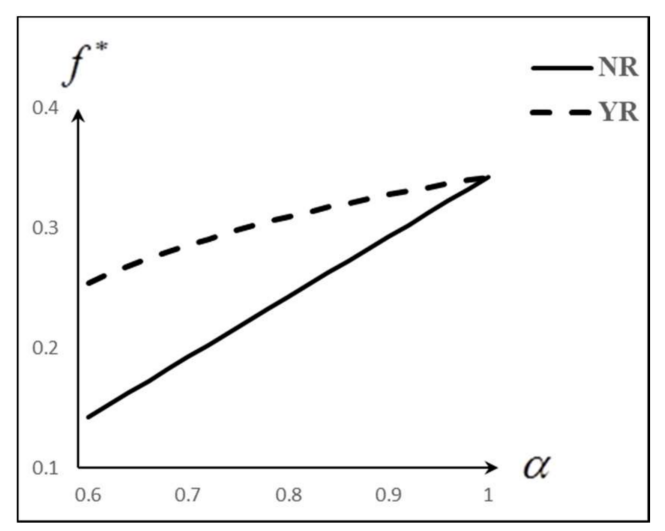

Figure 8. The optimal $f^{*}$ with respect to $\alpha$. 


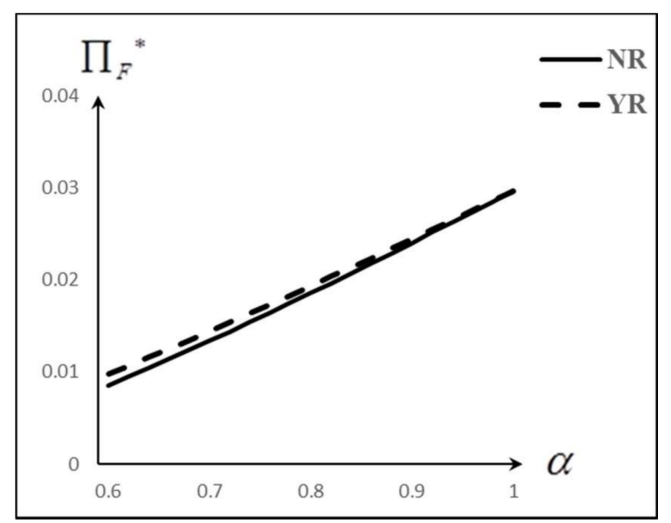

Figure 9. The optimal $\prod_{F}{ }^{*}$ with respect to $\alpha$.

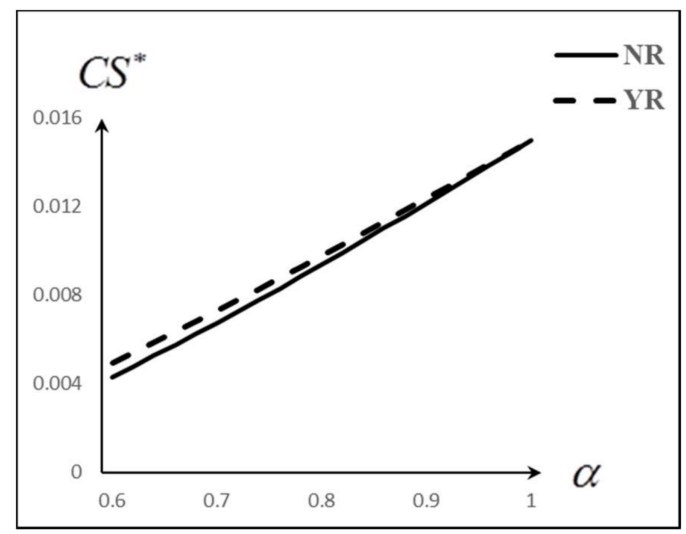

Figure 10. The optimal $C S^{*}$ with respect to $\alpha$.

Figures 6-10 imply that the increased average customer satisfaction rate of the product benefits the firm, consumers and the environment.

\section{Conclusions}

With the development of e-commerce, consumers' consumption habits have changed from offline shopping to online shopping. Some e-commerce giants such as Amazon.com, Tmall.com, JD.com dominate the e-commerce market. In these contexts, a few firms who produce green products under carbon tax policy sell their products on e-commerce platforms. Considering the relatively high online return rate, third-party sellers face the choices of whether or not to offer online return services. To help these third-party sellers to determine optimal strategies, this paper considers a firm producing and selling its product via an e-commerce platform. According to a firm with and without an online return service, we develop two theoretical models: i.e., model NR (a firm without a return service) and model YR (a firm with a return service). The paper investigates the optimal product retail prices, carbon reduction levels, referral fees, the firm's profits and consumer surpluses under models NR and YR, respectively; some managerial insights are presented as follows.

The optimal return strategy: a firm should not offer an online return service if the residual value of the returned product is relatively small; otherwise, the firm should offer it. Moreover, the optimal return strategy of the firm harms consumers.

The impacts of online return service: if the residual value of the returned product is relatively small (large), a firm will offer an online return service which harms (benefits) consumers. Moreover, if the residual value is relatively small (large), a firm with an online return service compared with 
that without a return service should increase (reduce) its product retail price and reduce (increase) its carbon reduction level while the platform should reduce (increase) its referral fee.

The impacts of carbon tax policy: Carbon tax policy harms the firm and consumers. Moreover, carbon tax policy has positive effects on the optimal product retail price and carbon reduction level while it has a negative effect on the optimal referral fee.

The impacts of the average customer satisfaction rate of the product: Improved average customer satisfaction rate of the product benefits the firm and consumers. Moreover, as the satisfaction rate increases, the firm should increase its product retail price and carbon reduction level and the platform should increase its referral fee.

There is still much space for future research. In our paper, we only consider a firm in the context of non-competition; thus, considering carbon reduction and return strategies in the context of competition is a future research direction. In addition, we assume that consumers need to undertake the shipping cost of returned products. Thus, it is interesting to investigate our problems if the firm undertakes the shipping cost of returned products. The paper hypothesizes that the unit carbon tax is an exogenous variable; thus, exploring the optimal carbon tax for the government via maximizing social welfare will be an extension of this study.

Author Contributions: J.W. analyzed the problems of determining optimal reduction and return strategies for firms by developing theoretical models, and she also wrote the draft of this paper. X.H. revised the written draft and provided theoretical and technical guidance for this paper.

Acknowledgments: This research is partly supported by the National Social Science Foundation of China (Grant No. 16CGL024) and the College of Humanities and Social Science Research Base Project of Jiangxi Province (2016) (Grant No. JD16150).

Conflicts of Interest: The authors declare no conflicts of interest.

\section{Appendix A}

The Proof of Theorem 1. Based on Table 2 and Equations (5) and (8), we can figure out the optimal profit of the firm under models NR and YR, which are given as follows:

$$
\begin{gathered}
\prod_{F}^{N R^{*}}=\left(a-c-h_{s}-h_{w}-e_{I} t\right)^{2} /(8 A) \\
\prod_{F}^{Y R^{*}}=\left(a+v+\alpha h_{s}-c-2 h_{s}-h_{w}-\alpha v-e_{I} t\right)^{2} /(8 A)
\end{gathered}
$$

Comparing the size relationship between the two profits, we have

$$
\prod_{F}^{Y R^{*}}-\prod_{F}^{N R^{*}}=\left(v-h_{s}\right)(1-\alpha)\left(2 a+v+\alpha h_{s}-2 c-3 h_{s}-2 h_{w}-\alpha v-2 e_{I} t\right) /(8 A)
$$

It is easy to verify that, if $0 \leq v<h_{s}$, we have $\prod_{F}^{Y R^{*}}-\prod_{F}^{N R^{*}}<0$; otherwise, $\prod_{F}^{Y R^{*}}-\prod_{F}^{N R^{*}} \geq 0$.

The Proof of Theorem 2. Based on Table 2 and Equations (7) and (10), we can figure out the optimal consumer surplus under models NR and YR, which can be presented as follows:

$$
\begin{gathered}
C S^{N R^{*}}=\alpha\left(a-c-h_{s}-h_{w}-e_{I} t\right)^{2} /\left(8 A^{2}\right) \\
C S^{Y R^{*}}=\alpha\left(a+v+\alpha h_{s}-c-2 h_{s}-h_{w}-\alpha v-e_{I} t\right)^{2} /\left(8 A^{2}\right)
\end{gathered}
$$

Comparing the size relationship between the two optimal consumer surplus, we have

$$
C S^{Y R^{*}}-C S^{N R^{*}}=\alpha\left(v-h_{s}\right)(1-\alpha)\left(2 a+v+\alpha h_{s}-2 c-3 h_{s}-2 h_{w}-\alpha v-2 e_{I} t\right) /\left(8 A^{2}\right)
$$

It is easy to verify that, if $0 \leq v<h_{s}$, we have $C S^{Y R^{*}}-C S^{N R^{*}}<0$; otherwise, $C S^{Y R^{*}}-C S^{N R^{*}} \geq 0$. 


\section{References}

1. Gale, W.; Brown, S.; Saltiel, F.; Center, U.B.T.P. Carbon Taxes as Part of the Fiscal Solution; Brookings Institution: Washington, DC, USA, 2013.

2. Ji, J.; Zhang, Z.; Yang, L. Carbon emission reduction decisions in the retail-/dual-channel supply chain with consumers' preference. J. Clean. Prod. 2017, 141, 852-867. [CrossRef]

3. Ji, S.; Zhao, D.; Peng, X. Joint Decisions on Emission Reduction and Inventory Replenishment with Overconfidence and Low-Carbon Preference. Sustainability 2018, 10, 1119.

4. Yi, Y.; Li, J. Cost-sharing contracts for energy saving and emissions reduction of a supply chain under the conditions of government subsidies and a carbon tax. Sustainability 2018, 10, 895.

5. U.S. Census Bureau. Quarterly Retail E-Commerce Sales 4th Quarter 2017. Available online: https://www. census.gov/retail/mrts/www/data/pdf/ec_current.pdf (accessed on 20 January 2018).

6. Cao, K.; He, P. The competition between B2C platform and third-party seller considering sales effort. Kybernetes 2016, 45, 1084-1108. [CrossRef]

7. Cao, K.; Xu, X.; Bian, Y.; Sun, Y. Optimal trade-in strategy of business-to-consumer platform with dual-format retailing model. Omega-Int. J. Manag. Sci. 2018. [CrossRef]

8. Vlachos, D.; Dekker, R. Return handling options and order quantities for single period products. Eur. J. Oper. Res. 2003, 151, 38-52. [CrossRef]

9. Poterba, J.M. Tax policy to combat global warming: On designing a carbon tax (No. w3649). Natl. Bur. Econ. Res. 1991. [CrossRef]

10. Roughgarden, T.; Schneider, S.H. Climate change policy: Quantifying uncertainties for damages and optimal carbon taxes. Energy Policy 1999, 27, 415-429. [CrossRef]

11. Metcalf, G.E. Designing a carbon tax to reduce US greenhouse gas emissions. Rev. Environ. Econ. Policy 2009, 3, 63-83. [CrossRef]

12. Zhou, Y.; Hu, F.; Zhou, Z. Pricing decisions and social welfare in a supply chain with multiple competing retailers and carbon tax policy. J. Clean. Prod. 2018, 190, 752-777. [CrossRef]

13. Nordhaus, W.D. Optimal greenhouse-gas reductions and tax policy in the "DICE" model. Am. Econ. Rev. 1993, 83, 313-317.

14. Goulder, L.H.; Mathai, K. Optimal $\mathrm{CO}_{2}$ abatement in the presence of induced technological change. J. Environ. Econ. Manag. 2000, 39, 1-38. [CrossRef]

15. Chen, X.; Hao, G. Sustainable pricing and production policies for two competing firms with carbon emissions tax. Int. J. Prod. Res. 2015, 53, 6408-6420. [CrossRef]

16. Yu, W.; Han, R. Coordinating a two-echelon supply chain under carbon tax. Sustainability 2017, 9, 2360. [CrossRef]

17. Wang, X.; Zhu, Y.; Sun, H.; Jia, F. Production decisions of new and remanufactured products: Implications for low carbon emission economy. J. Clean. Prod. 2018, 171, 1225-1243. [CrossRef]

18. Bettis, R.A.; Hall, W.K. Diversification strategy, accounting determined risk, and accounting determined return. Acad. Manag. J. 1982, 25, 254-264.

19. Rust, R.T.; Lemon, K.N.; Zeithaml, V.A. Return on marketing: Using customer equity to focus marketing strategy. J. Mark. 2004, 68, 109-127. [CrossRef]

20. Hsieh, C.C.; Lu, Y.T. Manufacturer's return policy in a two-stage supply chain with two risk-averse retailers and random demand. Eur. J. Oper. Res. 2010, 207, 514-523. [CrossRef]

21. Lau, H.S.; Lau, A.H.L. Manufacturer's pricing strategy and return policy for a single-period commodity. Eur. J. Oper. Res. 1999, 116, 291-304. [CrossRef]

22. Mukhopadhyay, S.K.; Setoputro, R. Optimal return policy and modular design for build-to-order products. J. Oper. Manag. 2005, 23, 496-506. [CrossRef]

23. Mukhopadhyay, S.K.; Setoputro, R. Reverse logistics in e-business: Optimal price and return policy. Int. J. Phys. Distrib. Logist. Manag. 2004, 34, 70-89. [CrossRef]

24. Li, Y.; Xu, L.; Li, D. Examining relationships between the return policy, product quality, and pricing strategy in online direct selling. Int. J. Prod. Econ. 2013, 144, 451-460. [CrossRef]

25. Bower, A.B.; Maxham, J.G., III. Return shipping policies of online retailers: Normative assumptions and the long-term consequences of fee and free returns. J. Mark. 2012, 76, 110-124. [CrossRef] 
26. Altug, M.S.; Aydinliyim, T. Counteracting strategic purchase deferrals: The impact of online retailers' return policy decisions. Manuf. Serv. Oper. Manag. 2016, 18, 376-392. [CrossRef]

27. Sahoo, N.; Dellarocas, C.; Srinivasan, S. The impact of online product reviews on product returns. Inf. Syst. Res. 2018. [CrossRef]

28. Cao, K.; Wang, J.; Dou, G.; Zhang, Q. Optimal trade-in strategy of retailers with online and offline sales channels. Comput. Ind. Eng. 2018. [CrossRef]

29. Cao, K.; Xu, X.; Wu, Q.; Zhang, Q. Optimal production and carbon emission reduction level under cap-and-trade and low carbon subsidy policies. J. Clean. Prod. 2017, 167, 505-513. [CrossRef] 